\title{
Análise da taxa de impermeabilização e tempo de concentração nas sub-bacias da área urbana de Barra do Garças - MT, Pontal do Araguaia - MT e Aragarças - GO
}

\section{Analysis of the waterproofing rate and time of concentration in urban sub-basins of Barra do Garças - MT, Pontal do Araguaia - MT e Aragarças - GO}

\author{
Greyce Bernardes de Mello Rezende, ${ }^{1}$ Sergio Murilo Santos de Araújo, ${ }^{2}$
}

Resumo: A presente pesquisa objetivou verificar as taxas de impermeabilização e tempo de concentração das sub-bacias presentes na área urbana de Barra do Garças - MT, Pontal do Araguaia - MT e Aragarças - GO. Tais variáveis podem auxiliar no ordenamento territorial da expansão urbana, bem como no planejamento urbano dessas cidades. Os resultados demonstraram que nas áreas já urbanizadas, o grau de impermeabilização e tempo de concentração das sub-bacias apresentaram níveis considerados "médios e altos", o que é preocupante, devido a relação dessas variáreis ao crescimento das vazões e volume escoado, e, consequentemente, aumento da frequência de inundações. Medidas não-estruturais, como legislação de uso do solo, com regras e incentivo para aumento de áreas permeáveis em lotes, bem como implantação de soluções alternativas de drenagem urbana que promovam o retardamento das águas pluviais, são soluções que podem ser implementadas na área em estudo.

Palavras-chaves: Drenagem urbana, urbanização, escoamento superficial.

Abstract: This study aimed to verify the waterproofing rates and time of concentration of these sub-basins present in the urban area of Barra do Garças - MT, Pontal do Araguaia - MT e Aragarças - GO. Such variables can assist in land use of urban expansion and the urban planning of these cities. The results demonstrated that in urban areas already, the degree of waterproofing and time of concentration of the sub-basins presented levels considered "medium and high", which is worrying, because the relationship of these variables to the growth of flows and runoff, and, consequently, increased frequency of floods. Non-structural measures such as land use legislation, with rules and incentive to increase permeable areas on lots, and implementation of alternative solutions to urban drainage that promote the slowing of rainwater, are solutions that can be implemented in the study area.

Key words: Urban drainage, urbanization, runoff.

\footnotetext{
*Autor para correspondência

Recebido para publicação em 10/10/2015; aprovado em 20/12/2015

${ }^{1}$ Doutora em Recursos Naturais pela Universidade Federal de Campina Grande (UFCG), professora do curso de Engenharia Civil da Universidade Federal de Mato Grosso (UFMT) - campus Araguaia, greycebernardes@yahoo.com.br

${ }^{2}$ Doutor em Geociências pela Universidade Estadual de Campinas (UNICAMP), professor no programa de pós-graduação em Recursos Naturais da

Universidade Federal de Campina Grande (UFCG), sergiomurilosaufcg@ gmail.com
} 


\section{INTRODUÇÃO}

De acordo com Tucci (1995), no início do século XX, a população urbana representava cerca de $15 \%$ da população mundial, enquanto que, ao final do mesmo século, atingiu a marca de 50\%, sendo esse processo de crescimento demográfico mais acentuado nos países em desenvolvimento. Nesses países, o crescimento urbano ocorrido tem sido significativo desde a década de 1970.

Para o autor, o avanço da urbanização de maneira desordenada sobre o meio natural acarreta diversos problemas, tais como: o desflorestamento, degradação progressiva das áreas de mananciais, ocupação de áreas inadequadas para a construção de habitações e a proliferação da atividade industrial em meio urbano. Os cursos d'água que se encontram inseridos em áreas urbanas são afetados diretamente por essa urbanização.

Além da deterioração da qualidade da água, rios que drenam bacias urbanas estão sujeitos a muitas pressões físicas. Superfícies impermeáveis extensas aumentam o escoamento superficial, dando aos rios urbanos um regime de fluxo com amplas e rápidas variações de descarga (OLIVERA; DEFEE, 2007). Há consequências também advindas das mudanças no regime de sedimentos do canal fluvial, o que frequentemente resultam em desmoronamento dos leitos dos rios e erosão das margens, bem como perda das funções do canal do rio como fonte de sedimentos, levando ao alargamento do canal do rio e instabilidade (BOOTH; HENSHAW, 2001; NIEZGODA; JOHNSON, 2005).

Esses impactos físicos, impostos pela urbanização dos rios, resultam em mudanças no estado da qualidade da água, grandes alterações nos ecossistemas aquáticos e ripícolas e em sua capacidade de se adaptar com sucesso a eventos extremos ou mudanças nas condições climáticas (BROWN et al., 2009; GROFFMAN et al., 2003; SHUKER; GURNELL; RACO, 2012).

De acordo com Tucci (1997), os principais tipos de inundações em áreas urbanas, têm suas causas em fatores específicos. Em relação ao fator urbanização, as mesmas são produzidas pela impermeabilização do solo e aumento dos volumes escoados através de condutos e canais. Já as inundações decorrentes da ocupação de áreas ribeirinhas ocorrem em rios de médio e grande porte. Para tanto, o rio extravasa do seu leito menor, ocupando o leito maior. A população desavisada tende a ocupar esse leito devido a sucessivos anos com enchentes pequenas ou pelo reduzido custo dessas áreas, sofrendo prejuízos nos anos de enchentes maiores.

Ressalta-se, através dessas definições, que as inundações, de modo geral, ocorrem quando a capacidade de armazenamento, atenuação e infiltração de água na bacia é reduzida, devido ao uso e ocupação do solo. Alterações produzidas por obras hidráulicas nos canais de macrodrenagem, também podem atuar como importantes indutores de inundações localizadas. Entretanto, apesar de serem problemas potencialmente impactantes na área urbana, extravasamentos de canais podem ocorrer em áreas não urbanizadas, como é o caso das ribeirinhas, já mencionadas anteriormente.

É importante salientar que a urbanização causa impactos diretos na drenagem urbana, visto que, comumente, a compactação e impermeabilização do solo geradas nesse processo têm como consequências diretas, a diminuição da infiltração e aumento do escoamento superficial, que podem levar à ocorrência de inundações nas áreas a jusante (FARIA; PEDROSA, 2005). Enfim, a impermeabilização e o uso e ocupação do solo de forma inadequada, bem como, o desmatamento e as condições técnicas inadequadas de condutos de escoamento pluvial geram um aumento de magnitude e frequência de inundações.

Segundo Tucci (2001), as bacias hidrográficas, em casos extremos, podem ter sua vazão de pico aumentada em até seis vezes o valor em condições naturais, em decorrência de alterações no escoamento superficial, por consequência da urbanização. Além disto, a queda da qualidade de vida nos centros urbanos está estritamente relacionada com os impactos da urbanização, como: a poluição dos mananciais, através dos efluentes urbanos; a disposição inadequada do esgoto, sistema pluvial e resíduos sólidos; a erosão e sedimentação que gera áreas degradadas; as ocupações inadequadas em áreas de risco e inundações nas áreas urbanas.

De maneira geral, a urbanização, quando vinculada ao aumento do grau de impermeabilização do solo, produz dois efeitos relevantes em relação ao destino das águas precipitadas. Um deles é o aumento do volume escoado pela superfície, em função da redução de áreas passíveis de infiltração e, consequentemente, aumento da vazão máxima. O outro efeito é a redução do tempo de percurso do escoamento superficial na bacia, haja vista que as canalizações, sarjetas e pátios propiciam a chegada mais rápida da água nos talvegues. Dessa forma, o amortecimento natural do escoamento na bacia tende a ser menor e, assim, a impermeabilização reduz o tempo de concentração das bacias.

O tempo de concentração pode ser definido como o tempo necessário para que toda a bacia contribua para o escoamento superficial em uma seção considerada. De forma simplificada, é o tempo que leva uma gota de água mais distante, até o trecho considerado na bacia (TOMAZ, 2002). Sendo assim, devido à urbanização, quanto maior a impermeabilização das áreas, menor será o tempo de concentração da bacia.

Portanto, verifica-se que o impacto negativo da urbanização, em sistemas fluviais, é amplo e multifacetado. (EVERARD; MOGGRIDGE, 2012). Nesse contexto, a elaboração de mapa de uso do solo das sub-bacias e, consequentemente, o grau de impermeabilização das mesmas apresenta indicativos de processos que podem interferir consideravelmente na expansão de eventos de inundações. Outro elemento importante é a análise do tempo de concentração das sub-bacias, que indica quais sub-bacias são mais influenciadas pelo escoamento superficial.

Assim, a partir da análise desses fatores, é possível fazer apontamentos sobre o grau de impacto gerado no canal fluvial e a urgência da presença de instrumentos normativos e ações do Poder Público no manejo das águas pluviais.

Em face ao exposto, este estudo objetivou verificar as taxas de impermeabilização e tempo de concentração das subbacias presentes na área urbana de Barra do Garças - MT, Pontal do Araguaia - MT e Aragarças - GO, para que posteriormente tal informação possa auxiliar no ordenamento territorial da expansão urbana, bem como no planejamento urbano destas cidades. 


\section{MATERIAL E MÉTODOS}

A área de estudo abrange a mancha urbana formada por três cidades, sendo: Aragarças, em Goiás, e Pontal do
Araguaia e Barra do Garças em Mato Grosso (Figura 1). Tais cidades são cortadas pelo rio Araguaia e das Garças, e também possuem diversos córregos inseridos em sua área urbana.

Figura 1. Mapa de Localização das cidades Aragarças - GO, Barra do Garças - MT e Pontal do Araguaia - MT

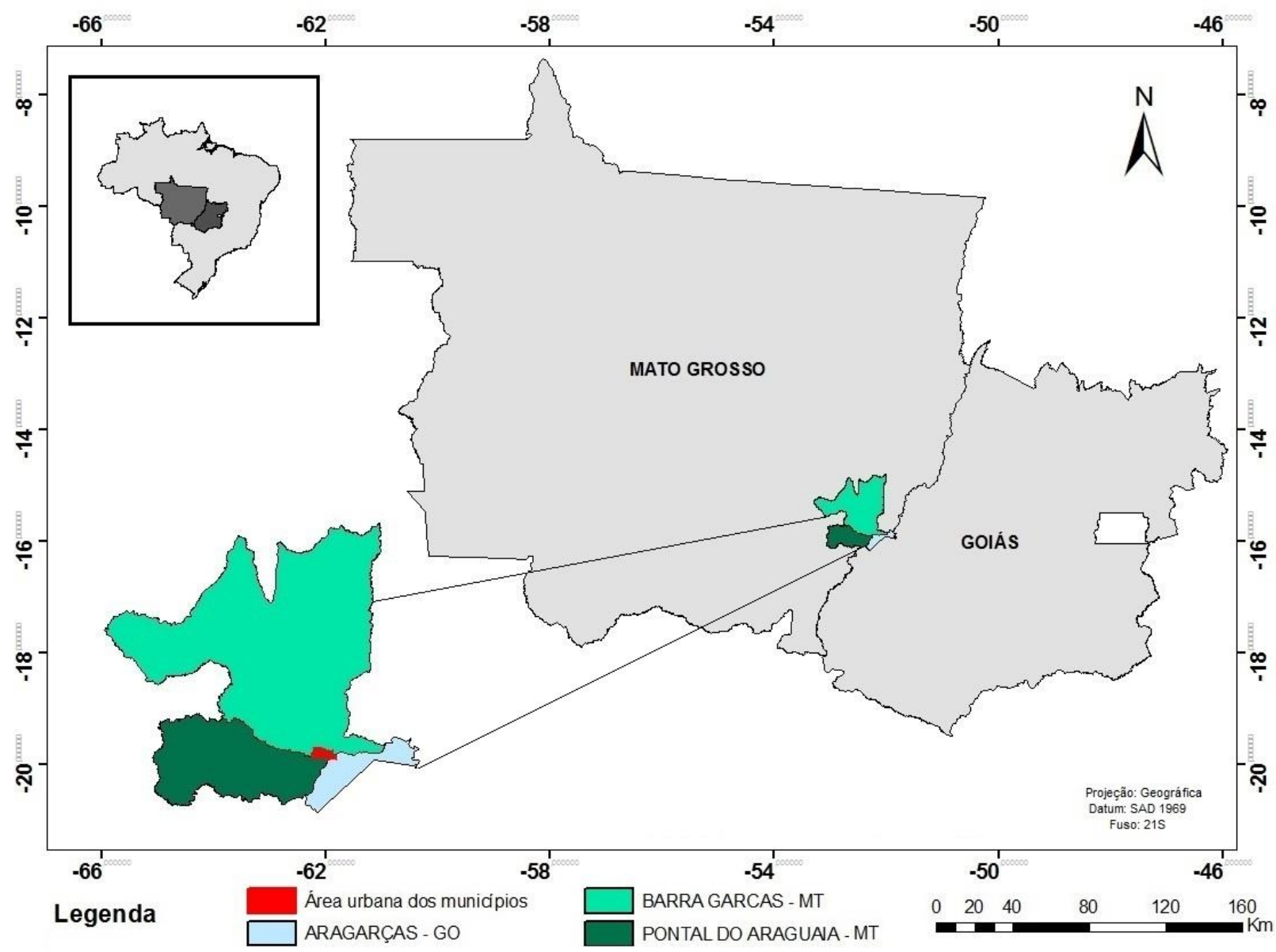

Fonte: Elaborado pelo autor.

Barra do Garças é um município do Estado de Mato Grosso, localizado na mesorregião do Nordeste Matogrossense e microrregião do Médio Araguaia. Com uma área territorial de $9.078,983 \mathrm{~km}^{2}$, apresenta uma população estimada de 58.398 habitantes (IBGE/2015) e uma densidade de $6,23 \mathrm{hab} . / \mathrm{km}^{2}$.

Pontal do Araguaia também é um município do Estado de Mato Grosso, localizado na mesorregião do Sudeste Matogrossense e microrregião de Tesouro. Com uma área territorial de $2.738,777 \mathrm{~km}^{2}$, apresenta uma população estimada de 6.128 habitantes (IBGE/2015) e uma densidade demográfica de $1,97 \mathrm{hab} . / \mathrm{km}^{2}$.

Já Aragarças, é um município do Estado de Goiás, localizado na mesorregião do Noroeste Goiano e microrregião de Aragarças. Com uma área territorial de $662,91 \mathrm{~km}^{2}$, apresenta uma população estimada de 19.583 habitantes (IBGE/2015) e uma densidade demográfica de 27,61 hab. $/ \mathrm{km}^{2}$.

Como já foi discutido, o avanço do processo de urbanização e as alterações promovidas no uso do solo geram consequências diretas na drenagem urbana, além de degradação dos corpos d'água por diversos fatores.
Dessa forma, foi confeccionado o mapa de uso do solo e cobertura vegetal e, posteriormente, detectou-se o grau de impermeabilização da sub-bacias delimitadas na pesquisa, fator que influencia diretamente na dinâmica fluvial.

Com técnicas de geoprocessamento, através do software ArcGis, as áreas foram mapeadas, conforme Carvalho (2011):

- Corpos d'água - espelhos d'água de lagos e rios;

- Vegetação - Presença contínua de vegetação arbórea ou arbustiva;

- Vegetação Residual e Usos Agrícolas - vegetação herbácea, acompanhada ou não de vegetação arbustiva ou arbórea. Em áreas urbanizadas, é encontrado normalmente em lotes vazios e nas margens de corpos d'água. Já nos ambientes não urbanizados, foram incluídas as áreas utilizadas para atividades agrícolas, mesmo com a presença de edificações isoladas:

- Área urbana com densidade baixa - As edificações estão em extensos terrenos e afastados entre si, com arruamento definido (Figura 2); 
Figura 2. Área urbana com densidade baixa de Barra do Garças - MT.

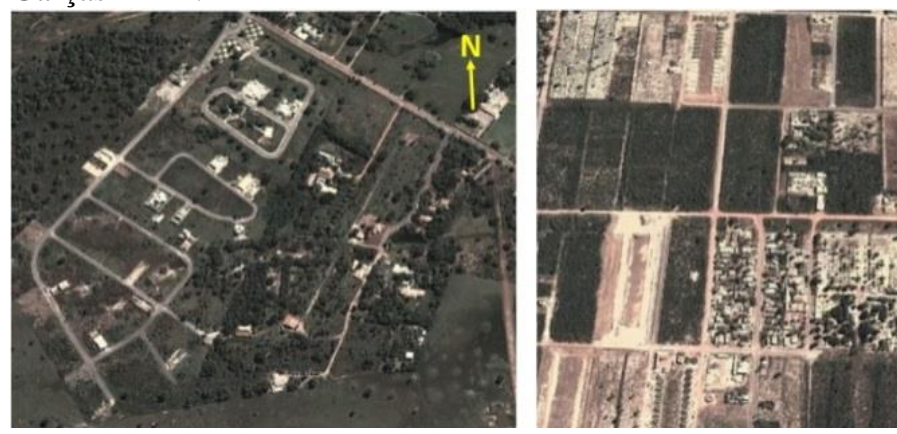

Fonte: Elaborado pela autora a partir de Imagem Google Earth - 2013

- Área urbana com densidade média - Edificações com áreas em que há presença de lotes vazios (Figura 3);

Figura 3. Área urbana com densidade média de Barra do Garças - MT

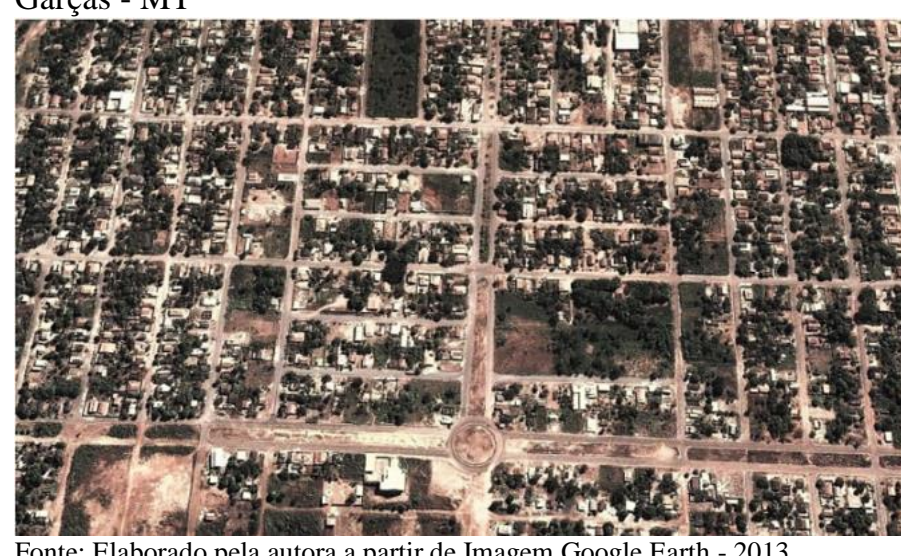

Fonte: Elaborado pela autora a partir de Imagem Google Earth - 2013

- Área urbana com densidade alta - áreas de ocupação contínua com arruamento definido, e pouquíssimos lotes desocupados (Figura 4).

Figura 4. Área urbana com densidade alta de Barra do Garças - MT

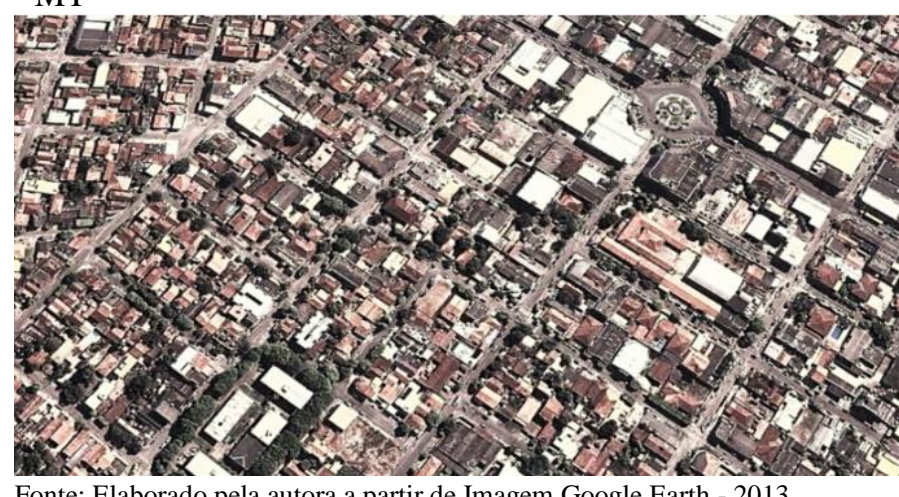

Fonte: Elaborado pela autora a partir de Imagem Google Earth - 2013

Após essa etapa, foi feito o levantamento da porcentagem de impermeabilização das sub-bacias. Essa análise resultou na classificação em quatro diferentes graus de impacto promovido pela urbanização, baseado no gráfico da
CWP (Center for Watersehd Protection), como pode ser visto na Figura 5.

Figura 5. Impacto das áreas impermeáveis nos rios em função de um conjunto de variáveis.

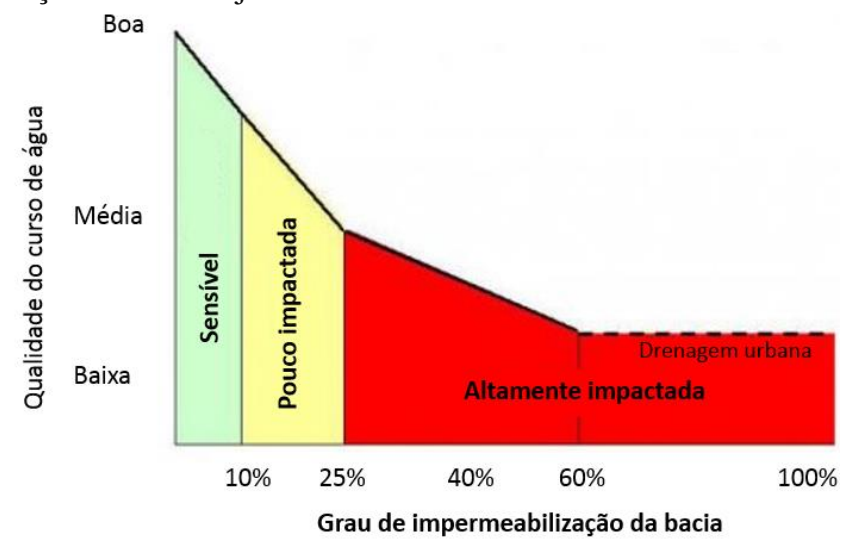

Fonte: Adaptado de CWP (2005).

Observa-se na Figura 5, os níveis de impacto no curso d'água a partir das porcentagens de impermeabilização da bacia. Tais níveis foram traduzidos na Tabela 1. Além do grau de impermeabilização, outra variável trabalhada se refere ao tempo de concentração (tc). Conforme relatado anteriormente, o tempo de concentração pode ser definido como o tempo necessário para que toda a bacia contribua para o escoamento superficial numa seção considerada.

Existem várias fórmulas para a estimativa do tempo de concentração, normalmente de caráter empírico ou representando ajuste de curvas para modelos hidrológicos. Evidentemente os resultados de diferentes fórmulas não convergem para um mesmo valor numérico. Algumas exigem poucos dados para sua alimentação, outras exigem uma quantidade maior de parâmetros.

Neste trabalho, foi utilizada fórmula que considere o grau de impermeabilização da bacia, visto que é um fator relevante em um estudo de macrodrenagem urbana. A partir de uma pesquisa na literatura, optou-se por utilizar a seguinte fórmula:

- $\quad$ Método de Germano:

$$
t c=18,628 \cdot \frac{L^{0,882}}{i m p^{0,272}}
$$

Em que:

$t c=$ tempo de concentração da bacia (min);

$L=$ comprimento do talvegue principal $(\mathrm{km})$;

imp $=$ porcentagem de área impermeável na bacia $(\%)$.

Após o cálculo dos tempos de concentração de cada subbacia, dividiram-se os valores em quatro níveis, demonstrados também na Tabela 1.

Segue abaixo a relação das variáveis utilizadas, no tocante às sub-bacias, baseado nos mapas confeccionados. 
Tabela 1. Variáveis utilizadas para as sub-bacias

Grau de impermeabilização

Acima de $60 \%$ de impermeabilização

Entre 25,01 e $60 \%$ de impermeabilização

Entre 10,01 e $25 \%$ de impermeabilização

Até $10 \%$ de impermeabilização

Tempo de concentração

3 a 20 minutos

20,01 a 40 minutos

40,01 a 100 minutos

Acima de 100 minutos

\section{Nível de impacto}

Muito alto

Alto

Médio

Baixo

Nível de impacto

\begin{tabular}{|l|}
\hline Muito alto \\
\hline Alto \\
\hline Médio \\
\hline Baixo \\
\hline
\end{tabular}

No item a seguir serão apresentadas as demarcações dos usos do solo e os resultados obtidos dos cálculos em relação à porcentagem de áreas impermeáveis de cada subbacia, bem como o respectivo tempo de concentração.

\section{RESULTADOS E DISCUSSÃO}

\section{Delimitação e mapeamento preliminar}

Inicialmente, foi feita a delimitação das sub-bacias. Elas foram extraídas de duas formas a seguir descritas: a) Para os cursos de água com nascente e foz dentro da área de estudo, a delimitação dos divisores de água foi realizada manualmente a partir do modelo digital de elevação do TOPODATA (Banco de dados geomorfométricos do Brasil) disponibilizado pelo INPE (Instituto Nacional de Pesquisas Espaciais). b) Para a extensão do rio Araguaia e rio Garças, as sub-bacias foram geradas automaticamente pelo programa TERRAVIEW, através do plugin TERRAHIDRO.

Para melhor análise, as sub-bacias foram numeradas, totalizando 55, (Figura 6). O objetivo é a demarcação dessas sub-bacias na área urbana dos municípios, contudo há algumas localizadas nos setores mais periféricos da área de estudo e ultrapassam tal limite, ocupando também áreas rurais.

Figura 6. Sub-bacias da área de estudo

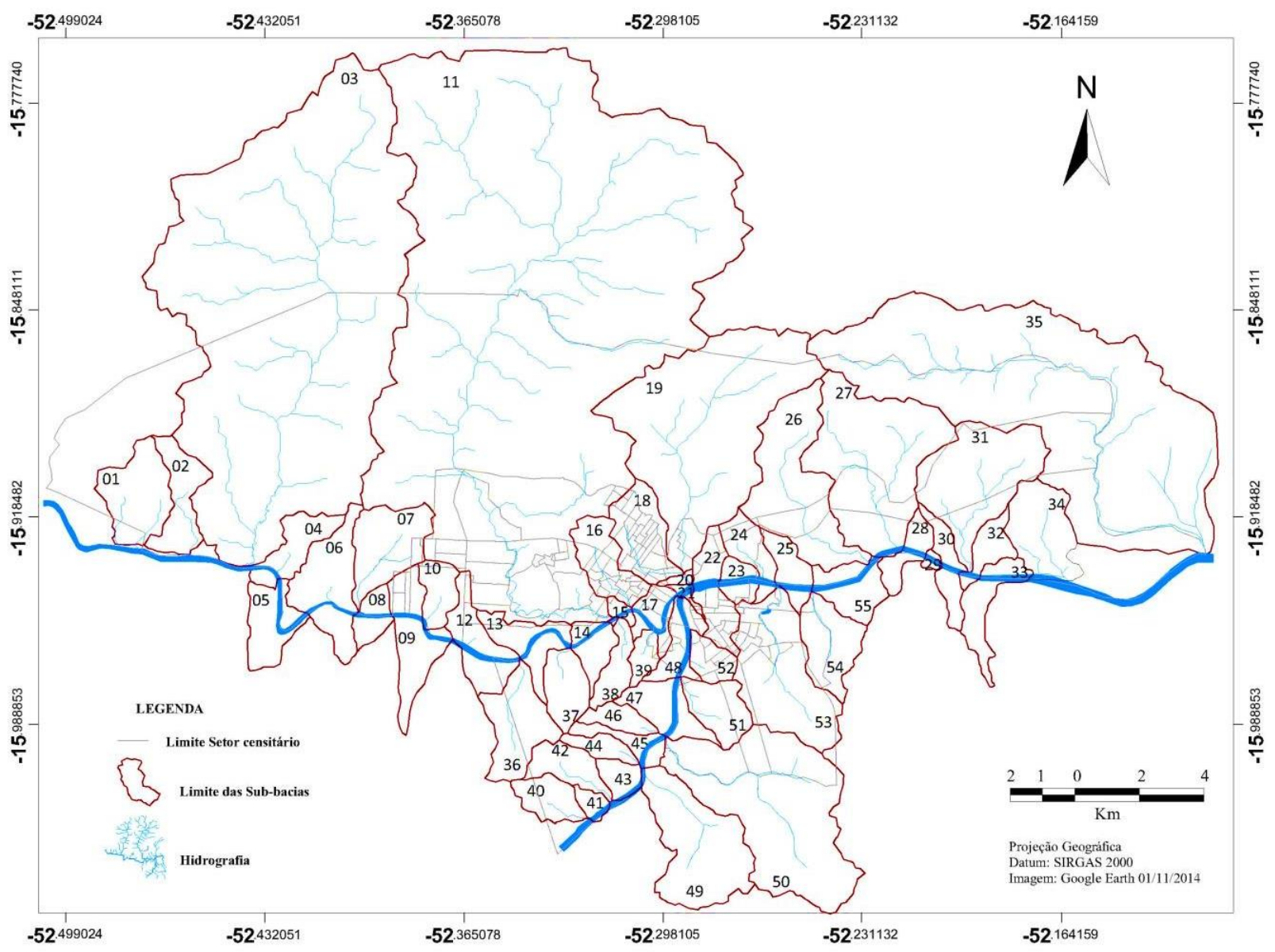

Fonte: Elaborado pela autora. 
Posteriormente foi elaborado Mapa de uso do solo com recorte para sub-bacias (Figura 7). Verifica-se, por meio desse mapa, que a área central das cidades analisadas possui uma urbanização mais densa, enquanto, nos setores mais periféricos, têm-se uma urbanização média e fraca. Tal característica é comum a cidades mononucleadas, onde serviços e comércios ficam alocados em seu centro, o que influencia em uma maior taxa de ocupação dessas áreas.

Figura 7. Mapa de uso do solo e vegetação com recorte para sub-bacias

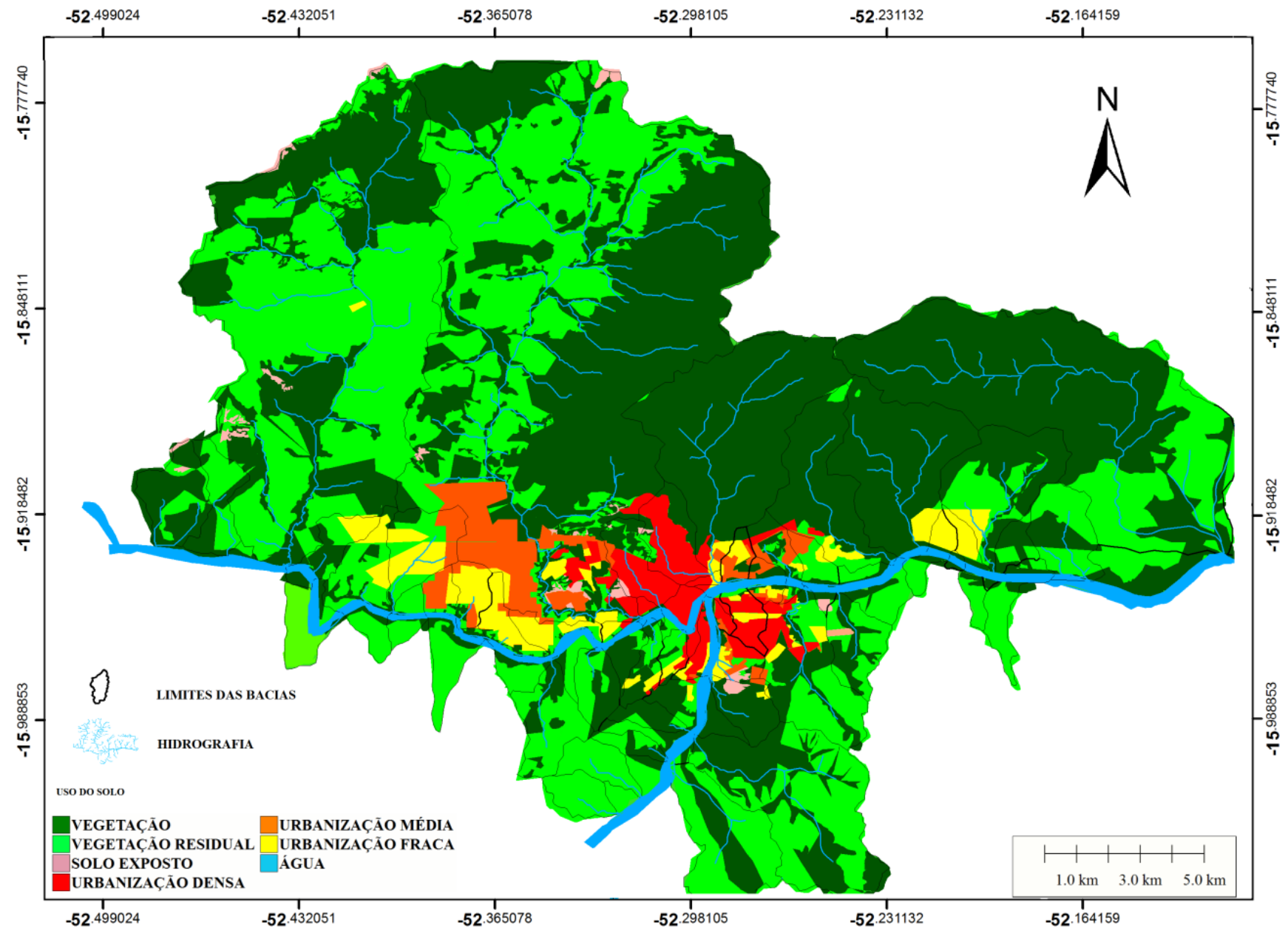

Fonte: Elaborado pela autora.

A demarcação dos usos do solo auxiliou na elaboração do mapa da Figura 8 o qual retrata, com maior precisão, a impermeabilização de cada sub-bacia. Através de imagem satélite landsat georreferenciada, montadas em um programa computacional do tipo $\mathrm{CAD}$, as áreas permeáveis foram demarcadas uma a uma visualmente, e posteriormente mensuradas.

Essas demarcações foram feitas por meio do comando POLYLINE do programa AUTOCAD, somadas e calculadas por meio do comando LIST, que mostra a área e o perímetro de cada polígono (Figura 8).

A demarcação seguiu o seguinte critério:

Áreas permeáveis - lotes e áreas sem construção ou qualquer tipo de impermeabilização. Também foram consideradas como áreas permeáveis as áreas verdes como praças e jardins, parques e bosques públicos, com cobertura vegetal predominante;
Áreas impermeáveis - todo o restante da área de estudo, ou seja, asfalto, pavimentações e edificações. Essas áreas foram levantadas quantitativamente de forma indireta, descontando, da área total analisada as demais áreas tomadas como permeáveis.

Verifica-se na Figura 8, que o setor central da cada cidade de Barra do Garças - MT, Aragarças - GO e Pontal do Araguaia - MT se encontra bastante impermeabilizado, seguido de bairros como Nova Barra e Vila Maria em Barra do Garças (trechos das sub-bacias 07, 09, 10 e11). Nas áreas de expansão urbana e trechos da área rural, as áreas impermeáveis correspondem a sedes de fazendas, e rodovias.

Esse mapa possibilitou o cálculo de índices para as variáveis relacionadas à porcentagem de área impermeabilizada por sub-bacia e o tempo de concentração apresentados a seguir. 
Figura 8. Mapa com demarcação de áreas permeáveis e impermeáveis

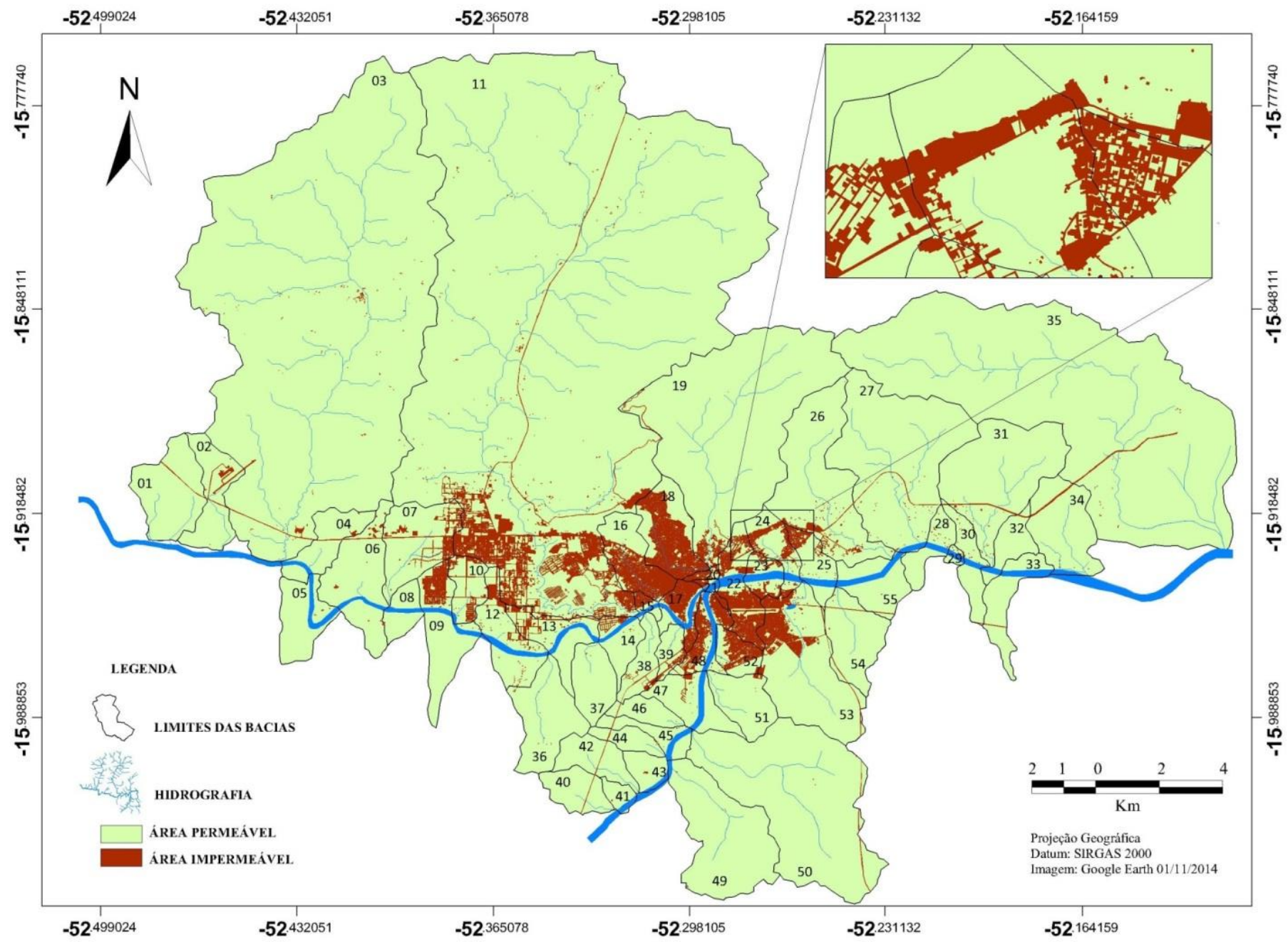

Fonte: Elaborado pela autora.

Variáveis: Grau de impermeabilização e Tempo de concentração

Para essas duas variáveis, foram trabalhados quatro níveis: baixo, médio, alto e muito alto.

No tocante ao grau de impermeabilização, esses níveis se classificam em: a) baixo - sub-bacias com até $10 \%$ de sua área impermeabilizada; b) médio - taxa de impermeabilização entre 10,01 e $25 \%$; c) alto - taxa entre $25,01 \%$ e $60 \%$ e; d) muito alto, acima de $60 \%$ da sub-bacia impermeabilizada.

De acordo com a Figura 9, a sub-bacia 20, foi a única a apresentar nível muito alto de impermeabilização, correspondendo ao setor cidade velha (centro antigo da cidade de Barra do Garças), e possuindo $62 \%$ de área impermeável. 
Figura 9. Grau de impermeabilização das sub-bacias

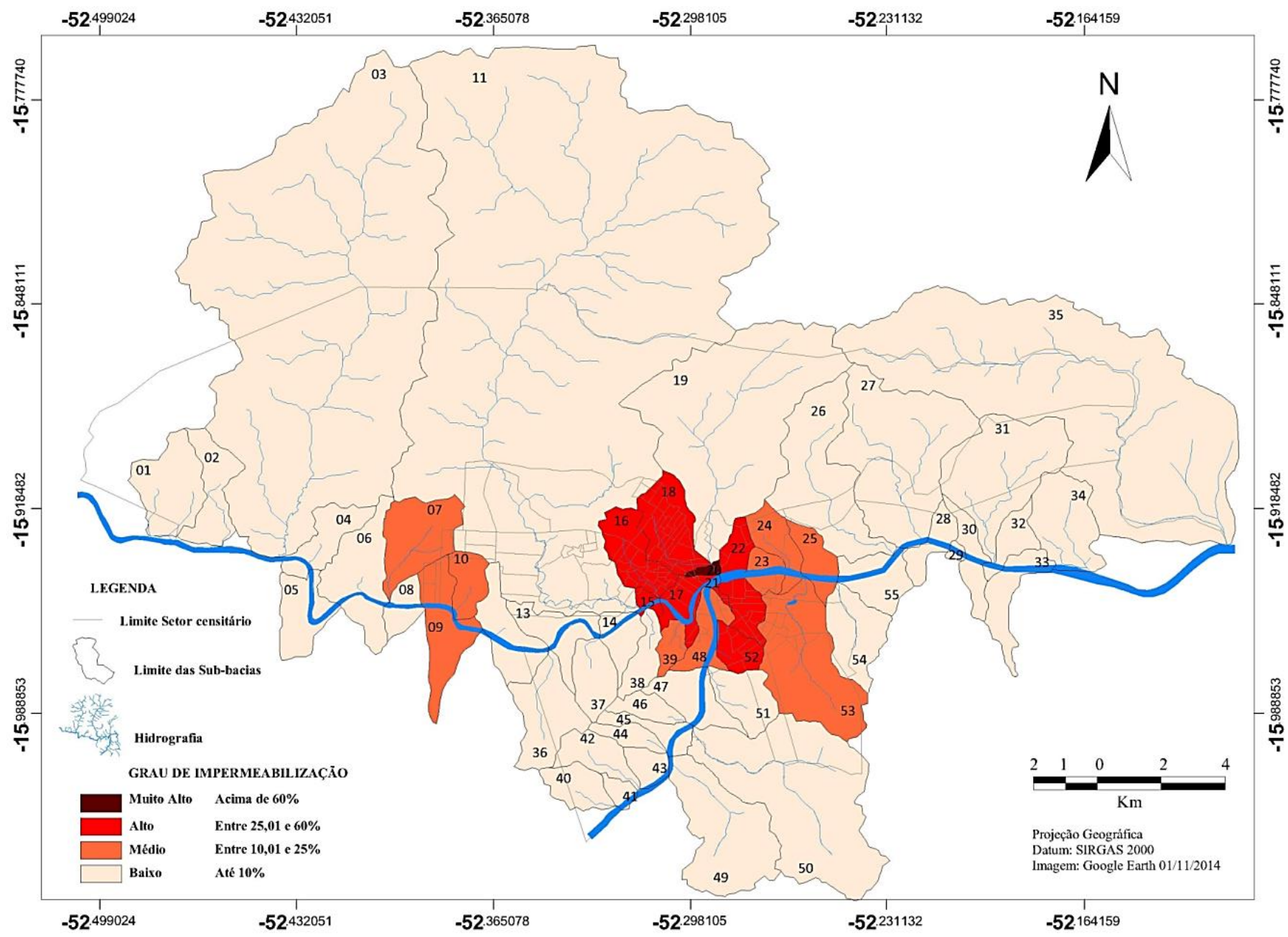

Fonte: Elaborado pela autora.

Das 55 sub-bacias, sete apresentam nível alto, são elas: as sub-bacias $15,16,17,18,21,22$ e 52 . A maioria dessas sub-bacias coincide com o setor central das cidades de Barra do Garças-MT e Aragarças - GO, o que é um fato comum aos setores mais centrais de cidades, que normalmente apresentam maiores índices de impermeabilização.

A maior parte da área urbanizada de Pontal do Araguaia - MT está inserida em sub-bacias com nível médio de impermeabilização (sub-bacias 39 e 48). Da mesma forma, trechos dos bairros Nova Barra e Vila Maria em Barra do Garças - MT (sub-bacias 7, 9 e 10) e a sub-bacia do córrego Róla em Aragarças - GO (sub-bacia 53) também possuem nível médio de impermeabilização.

Já as sub-bacias que estão na área periférica, são aquelas que apresentaram menores taxas de impermeabilização.
Nesse sentido, a Figura 10 sintetiza a porcentagem de subbacias contidas em cada nível. Verifica-se que a maioria das sub-bacias possui nível baixo, no tocante ao grau de impermeabilização $(69,09 \%)$, o que denota um resultado positivo.

Todavia, ressalta-se que a delimitação de perímetro urbano desses municípios é bastante extensa e abarca áreas com pouca urbanização o que contribuiu para este resultado. Já as sub-bacias que estão inseridas na parte urbanizada apresentaram níveis alto e médio de impermeabilização, o que é preocupante, devido ao impacto que gera na drenagem urbana. A única exceção é a sub-bacia 11 que, mesmo contendo trecho inserido na área urbanizada com extensas áreas impermeáveis, apresentou nível baixo, devido à sua grande dimensão.

Figura 10. Porcentagem de sub-bacias de acordo com o nível de impermeabilização.

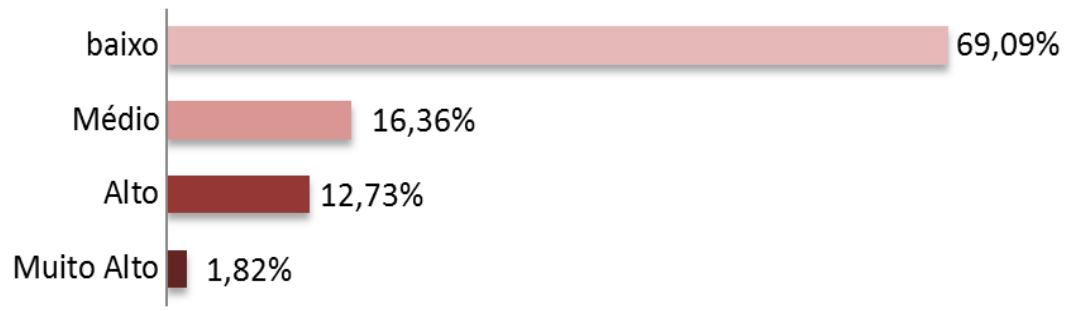

Fonte: Elaborado pela autora. 
Conclui-se que o planejamento urbano dessas cidades deve considerar o impacto da expansão urbana, especialmente de futuros loteamentos sobre a drenagem de águas pluviais, visto que, nas áreas já urbanizadas, o grau de impermeabilização das sub-bacias apresentou nível alto e médio, o que acarreta aumento do volume do escoamento superficial e aumento do pico da vazão máxima das cheias.
Em relação ao tempo de concentração, os níveis se referem aos seguintes intervalos: a) baixo - acima de 100 minutos; b) médio - 40,01 a 100 minutos; c) alto - 20,01 a 40 minutos e; d) muito alto - de 3 a 20 minutos.

No mapa da Figura 11, verifica-se que as pequenas subbacias apresentaram menores valores e consequentemente maiores níveis: alto e muito alto, seguidas pelas bacias médias, como é o caso das sub-bacias 26, 31, 53,54 e 55.

Figura 11. Mapa com a demarcação dos tempos de concentração estimados para cada sub-bacia

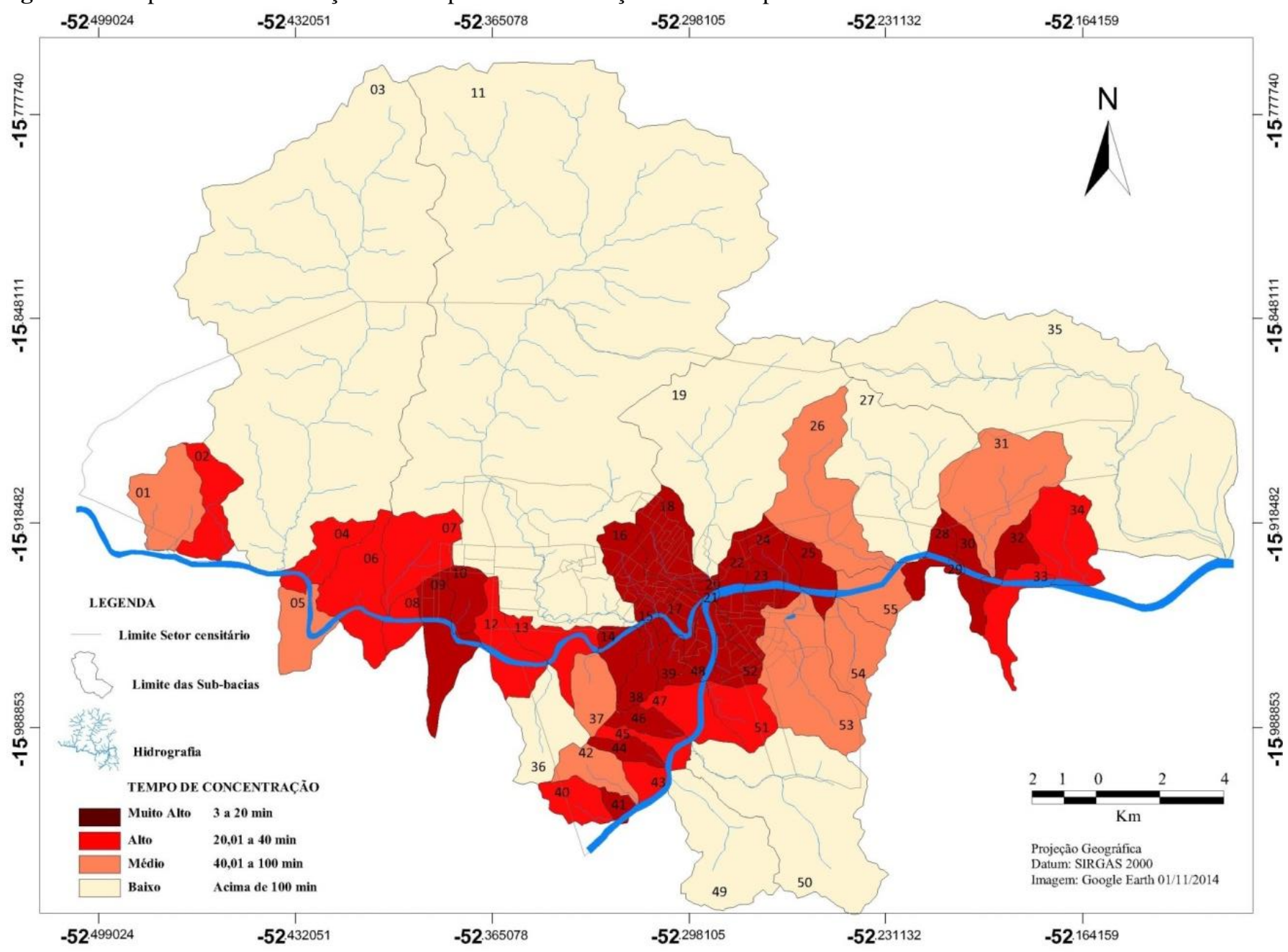

Fonte: Elaborado pela autora.

As sub-bacias que apresentaram maiores valores de tempo de concentração são aquelas maiores, periféricas e que possuem uma área permeável considerável (nível baixo). Também é possível notar a tendência dos tempos de concentração serem maiores em sub-bacias de conformação mais arredondada. Um contraexemplo disso é a sub-bacia 53, a qual é drenada pelo córrego Róla em Aragarças. Nota-se que essa sub-bacia apresenta forma mais afilada e, embora apresente área considerável de superfície impermeabilizada, gerou tempo de concentração intermediário. Esses resultados confirmam a influência da forma das bacias no tempo de concentração, haja vista que, em bacias mais arredondadas, há a tendência de redução do tempo de concentração e de aumento dos picos de enchente.
Ainda de acordo com o Figura11, verifica-se que todas as sub-bacias que margeiam o rio das Garças e o rio Araguaia apresentaram baixos valores de tempo de concentração, o que pode contribuir significamente para o aumento na frequência e no volume das inundações dessas áreas.

Por fim, a Figura 12 sintetiza a porcentagem de subbacias contidas em cada nível. Verifica-se que grande porcentagem delas possui nível muito alto $(43,64 \%)$ e alto $(25,45 \%)$ no tocante ao tempo de concentração (tc). Portanto, $69,09 \%$ dessas sub-bacias possuem tc entre 2 a 40 minutos, o que significa que o tempo necessário para que toda sub-bacia contribua para o escoamento superficial será relativamente baixo. 
Figura 12. Porcentagem de sub-bacias de acordo com o nível referente ao tempo de concentração

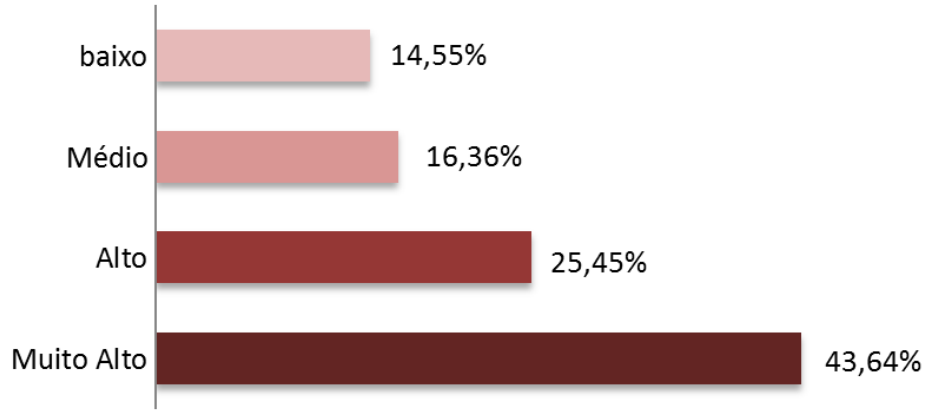

Fonte: Elaborado pela autora

Para o cálculo do tempo de concentração foi utilizada equação que considera variáveis como área da bacia, comprimento do talvegue e porcentagem de área impermeabilizada. Dentre elas, a quantidade de área impermeabilizada é a única variável que pode ser trabalhada no planejamento urbano.

Mais uma vez, salienta-se a importância de medidas não-estruturais, como legislação de uso do solo, com regras e incentivo para aumento de áreas permeáveis em lotes e a regulação da expansão urbana de futuros loteamentos. Conforme demonstrado, há uma estreita relação entre área impermeabilizada e tempo de concentração, e as medidas citadas colaboram de forma considerável e positiva na drenagem urbana.

\section{CONCLUSÕES}

Evidencia-se que o impacto negativo da urbanização em sistemas fluviais é amplo e multifacetado. A urbanização, estando vinculada ao aumento do grau de impermeabilização do solo, gera redução do tempo de concentração, crescimento das vazões e volume escoado e, consequentemente, aumento da frequência de inundações. Na área de estudo, conclui-se que o planejamento urbano-ambiental dessas cidades precisa considerar o impacto da expansão urbana sobre a drenagem de águas pluviais, notadamente em futuros loteamentos. Isso porque, nas áreas já urbanizadas, o grau de impermeabilização e tempo de concentração das sub-bacias apresentaram níveis "médios e altos", o que é preocupante.

Importante destacar que a delimitação de perímetro urbano desses municípios é bastante extensa, principalmente de Barra do Garças - MT, onde esse perímetro abrange áreas já loteadas, mas não ocupadas e com muitos lotes vagos, além de extensas áreas ainda não loteadas. Essa expansão urbana, de forma não coesa, compromete a preservação dos recursos naturais das áreas não urbanizadas e é nessa seara que devem ser adotadas medidas não-estruturais, como legislação de uso do solo, com regras e incentivo para aumento de áreas permeáveis em lotes.

Além disso, o planejamento territorial através da Lei de uso e ocupação do solo ou Plano Diretor, com o mapeamento do zoneamento, com zonas de conservação e proteção ambiental, bem como instrumentos de comando e controle efetivos, colaboram para o desenvolvimento das cidades concomitante à preservação de seus recursos naturais. Outrossim, em razão da área de estudo ser composta por diversas sub-bacias, deve-se também iniciar a implantação de soluções alternativas de drenagem urbana, que promovam o retardamento das águas pluviais, evitando a transferência rápida das mesmas para jusante. Algumas sugestões a serem adotadas são a utilização de pavimentos permeáveis/porosos em áreas públicas (praças, parques e canteiros); valetas de infiltração, adjacentes a ruas e estradas, ou estacionamentos; bacias de percolação e retenção.

\section{REFERÊNCIAS BIBLIOGRÁFICAS}

TUCCI, C. E. M. Inundações Urbanas. In: TUCCI, C.E.M.; PORTO, R. L. L.; BARROS, M.T. (Orgs.). Drenagem Urbana. Porto Alegre: Editora da UFRG e ABRH, 1995. p. 15-36.

Plano Diretor de Drenagem Urbana: princípios e concepção. Revista Brasileira de Recursos Hídricos, Porto Alegre, v.2, n.2, p.5-12, 1997.

Drenagem Urbana. In: TUCCI, C.E.M. (Org.). Hidrologia: ciência e aplicação. 2 ed., São Paulo: Editora Universidade EDUSP/ABRH, 2001.

BROWN, L. R. et al. Urban streams across the USA: lessons learned from studies in 9 metropolitan areas. The North American Benthological Society. v. 28, n.4, p.10511069, 2009.

BOOTH, D. B.; HENSHAW, P. C. Rates of channel erosion in small urban streams. In: WIGMOSTA, M; BURGES, S. (Eds.). Land Use and Watersheds: Human Influence on Hydrology and Geomorphology in Urban and Forest Areas. AGU Monograph Series, Water Science and Application, v. 2, 2001, p. 17-38.

CARVALHO, L. E. P. Os descaminhos das águas na metrópole: a socionatureza dos rios urbanos. 2011. 176 f. Tese (Doutorado em Geografia) - Centro de Filosofia e Ciências Humanas, Programa de pós-graduação em Geografia, Universidade Federal de Pernambuco, Recife, 2011.

CWP - CENTER FOR WATERSHED PROTECTION. Urban Subwatershed Restoration Manual Series. An Integrated Framework to Restore Small Urban Watersheds. Manual 1. 116p. 2005. 
EVERARD, M.; MOGGRIDGE, H. L. Rediscovering the value of urban rivers. Urban Ecosyst. n.15, p. 293-314, 2012.

FARIA, R.; PEDROSA, A. Impactos da Urbanização na Degradação do solo urbano e sua relação com o incremento de inundações urbanas em Santa Maria da Feira. In: INTERNATIONAL SYMPOSIUM IN LAND DEGRADATION AND DESERTIFICATION, 2005. Uberlândia. Anais... União Geográfica e Comland. Disponível em: http:<//web.letras.up.pt/aspedos/>. Acesso em: 10 set. 2014.

GROFFMAN, P. M. et al. Down by the riverside: urban riparian ecology. Frontiers Ecology and the Environment, v.1, n.6, p. 315-321, 2003.

OLIVERA, F.; DEFEE, B. B. Urbanization and its effect on runoff in the whiteoak Bayou watershed, Texas. Journal of the American Water Resources Association, v. 43, n. 1, p. 170-182, 2007.
IBGE - INSTITUTO BRASILEIRO DE GEOGRAFIA E ESTATÍSTICA. População estimada 2015. Disponível em:

<http://www.cidades.ibge.gov.br/xtras/perfil.php?lang= $\&$ codmun $=510180>$. Acesso em: $30 \mathrm{dez} .2015$.

NIEZGODA, S. L.; JOHNSON, P. A. Improving the urban stream restoration effort: identifying critical form and processes relationships. Environmental Management. v. 35, n. 5, pg. 579-592, 2005.

SHUKER, L., GURNELL, A. M. e RACO, M. Some simple tools for communicating the biophysical condition of urban rivers to support decision making in relation to river restoration. Urban Ecosystems, v. 15, n. 2, p. 389-408, 2012.

TOMAZ, P. Cálculos hidrológicos e hidráulicos para obras Municipais. São Paulo: Navegar, 2002. 